\title{
Caracterização molecular de cultivares de cebola por marcadores RAPD
}

\author{
Daniela L Leite; Denilson Anthonisen \\ 1Embrapa Clima Temperado, C. Postal 403, 96001-970 Pelotas-RS; daniela@cpact.embrapa.br
}

\begin{abstract}
RESUMO
Em plantas alógamas, as cultivares constituem uma fonte de variação genética planta-a-planta no qual o melhorista pode obter novos materiais. A variabilidade genética entre indivíduos ou populações tem sido medida através de marcadores moleculares. O objetivo deste trabalho foi avaliar molecularmente, através da análise de RAPD (Random Amplified Polimorphic DNA), a diversidade genética existente em um grupo de cultivares de cebola recomendadas para o cultivo na Região Sul do Brasil. Foram analisados 11 iniciadores em DNAs provenientes de um total de 90 plantas individuais oriundas das cultivares Baia Periforme, Bola Precoce, BRS Cascata, Crioula, Primavera e Roxa. As plantas foram genotipadas através dos produtos visualizados em gel de agarose e uma matriz de presença/ausência de bandas foi utilizada nas análises de similaridade genética (coeficiente de Jaccard) e de agrupamento pelo método UPGMA. Os 11 iniciadores geraram $140(86,4 \%)$ bandas polimórficas. O número de fragmentos por iniciador variou de 10 (UBC105) até 18 (OPA10; OPC11; OPI1) com uma média de 15 bandas por iniciador. A técnica de RAPD mostrou-se eficiente na caracterização molecular, permitindo a formação de grupos de cultivares de acordo com a sua população de origem, com uma similaridade média de 63\%. Conclui-se que as cultivares de cebola recomendadas para a Região Sul do Brasil, apresentam divergência genética, com potencial de serem exploradas por melhoristas, no desenvolvimento de genótipos superiores.
\end{abstract}

Palavras-chave: Allium cepa L., recursos genéticos, melhoramento genético, análise de agrupamento.

\begin{abstract}
Molecular characterization of onion cultivars by RAPD markers

In alogam plants, the cultivars constitute a source of plantto-plant genetic variation from which the breeder can obtain new materials. Genetic variability among individuals or populations has been measured through molecular markers. The objective of this work was to evaluate the genetic diversity in a group of onion cultivars recommended for cultivation in the Southern Region of Brazil by RAPD (Random Amplified Polimorphic DNA) analysis. Eleven primers were employed to the characterization of 90 individual plants from Baia Periforme, Bola Precoce, BRS Cascata, Crioula, Primavera and Roxa cultivars. The plants were genotyped through the products visualized in agarose gel and a matrix of presence/absence of bands was used in the analyses of genetic similarity (coefficient of Jaccard) and grouping by UPGMA method. The 11 primers generated 140 $(86,4 \%)$ polymorphic bands. The number of fragments per primer varied from 10 (UBC105) to 18 (OPA10; OPC11; OPI1) with an average of 15 bands per primer. The RAPD technique was efficient in the molecular characterization, allowing the formation of groups of cultivars according of its origin population, with an average similarity of $63 \%$. The onion cultivars recommended for the Southern Region of Brazil present genetic divergence, with potential to be explored by breeders for the development of superior genotypes.
\end{abstract}

Keywords: Allium cepa L., genetic resources, plant breeding, cluster analysis.

(Recebido para publicação em 29 de agosto de 2008; aceito em 25 de novembro de 2009) (Received in August 29, 2008; accepted in November 25, 2009)

$\mathrm{O}^{\mathrm{r}}$ riginária da Ásia Central, a cebola é cultivada há mais de 5000 anos; pertence à família Alliaceae e é classificada botanicamente como Allium cepa L. (Hanelt, 1990). Como característica marcante, destaca-se o odor pungente, liberado ao cortar-se o bulbo (Lancaster \& Boland, 1990).

A cebola é uma espécie diplóide, $2 \mathrm{n}=2 \mathrm{x}=16$, com um número básico de cromossomos $x=8$. Comparada a outras importantes culturas, poucos genes foram identificados em cebola. Somente cerca de 20 genes foram caracterizados por estudos de herança (Cramer \& Havey, 1999). Dificuldade de obtenção de informações genéticas na cultura da cebola é atribuída ao fato de ser de ciclo bianual, ao tempo necessário para a realização de análises de segregação e a sua natureza alógama, portanto heterozigota, com importante depressão de vigor quando autofecundada (Brewster, 1994; Goldman et al., 2000). Além desses fatores, a cebola possui um dos maiores genomas de todas as plantas cultivadas (King et al., 1998) o que torna os estudos de genética molecular mais difíceis.

A cebola possui diversidade genética ampla, condicionada, em parte, por sua natureza predominantemente alógama. Uma grande variação de cultivares locais e cultivares melhoradas desenvolveram- se ao longo dos séculos em resposta aos diversos climas e preferências culinárias do mundo (Leite, 2007).

No Brasil, o marco inicial do cultivo de cebola ocorreu com a chegada de imigrantes portugueses e açorianos que colonizaram a região de Rio Grande e Pelotas no início do século XIX (França \& Candeia, 1997). As cultivares introduzidas por esses colonizadores estiveram expostas à ação da seleção natural e humana, constituindo populações distintas, adaptadas às condições locais do ambiente. Esses fatores garantiram a formação de um valioso banco de genes desta espécie no Sul do Brasil (Barbieri et al., 2005) que vem sendo conservado 
em bancos ativos de germoplasma da Embrapa, a longo prazo pela Embrapa Recursos Genéticos e Biotecnologia, em Brasília-DF e a médio prazo na Embrapa Clima Temperado, em Pelotas-RS.

No Brasil, a maioria das cultivares de cebola é de polinização aberta $(\sim 90 \%)$ e foram selecionadas a partir das populações de Baia Periforme e Crioula (Melo \& Boiteux, 2001), as quais podem servir de base para o desenvolvimento de novos materiais.

A tendência atual do melhoramento genético é a utilização e a integração das metodologias tradicionais com as modernas técnicas biotecnológicas. Técnicas de análise em nível de DNA, como o RAPD (Randon Amplified Polymorphic DNA), têm oferecido melhor resolução em estudos de diversidade genética, devido ao número ilimitado de marcadores que utilizam (Klaas \& Friesen, 2002). Wilkie et al. (1993) demonstraram a aplicabilidade de marcadores RAPD em análises genéticas do gênero Allium, quando acessaram o grau de polimorfismo dentro do gênero e em estudos genéticos em cebola.

Os marcadores RAPD foram utilizados, em cebola, por Bradeen \& Havey (1995), com o objetivo de avaliar a integridade de duas linhagens endogâmicas parentais e de 59 famílias $\mathrm{F}_{3}$ resultantes. De 580 iniciadores examinados, 53 revelaram polimorfismos e apenas 12 apresentaram segregação mendeliana nas famílias. Havey et al. (1996) atribuíram o baixo nível de polimorfismo encontrado, à heterozigose das linhagens parentais ou à ambigüidade na presença de bandas polimórficas entre as famílias $\mathrm{F}_{3}$. Ao mesmo tempo, os autores consideraram que este estudo se constituiu em uma análise robusta pela técnica de RAPD.

Os marcadores de RAPD, RFLP e morfológicos foram utilizados para a construção de um mapa genético de cebola (King et al., 1998; Cramer \& Havey, 1999).

Buzar (2005) empregou a técnica de RAPD na estimativa da variabilidade genética de uma coleção de 24 cultivares elite de cebola, representativa de uma fração significativa dos genótipos adaptados para cultivo no Brasil. O es- tudo permitiu, com a utilização de dois iniciadores, previamente testados como polimórficos, a comprovação da alta diversidade entre as cultivares.

Masuelli \& Galmarini (1996) realizaram com sucesso a caracterização molecular de quatro cultivares argentinas de cebola por meio da técnica RAPD.

O objetivo deste trabalho foi avaliar, através da técnica de RAPD, a variabilidade genética existente em um grupo de cultivares de cebola recomendadas para cultivo na Região Sul do Brasil.

\section{MATERIAL E MÉTODOS}

Foram analisadas 90 plantas individuais das cultivares Baia Periforme (10 plantas), Bola Precoce (10 plantas), BRS Cascata (20 plantas), Crioula (20 plantas), Primavera (20 plantas) e Roxa (10 plantas). Os procedimentos usados na extração de DNA, a partir de amostras foliares, e sua amplificação pelo método de RAPD foram os descritos por Ferreira \& Grattapaglia (1998) com algumas modificações: cada reação foi realizada em um volume final de $13 \mu$, contendo tampão (20 mM Tris-HCl, $50 \mathrm{mM} \mathrm{KCl,}$ pH 8,4), $\operatorname{MgCl} 2$ (2 mM), dNTPs $(0,25$ $\mathrm{mM})$, BSA purificada $(0,2 \mu \mathrm{g})$, iniciador $(0,4 \mu \mathrm{M})$, taq polimerase (1U) e DNA genômico (20 ng).

As amplificações foram realizadas em tubos Eppendorf $®$ em um termociclador (RoboCycler 96 Temperature Cycler - Stratagene) programado para 40 ciclos repetidos nas seguintes condições: um minuto a $92^{\circ} \mathrm{C}$ (desnaturação), um minuto a $35^{\circ} \mathrm{C}$ (anelamento) e dois minutos a $72^{\circ} \mathrm{C}$ (extensão). Após, foi efetuada uma etapa final de extensão de cinco minutos a $72^{\circ} \mathrm{C}$.

Foram usados 11 iniciadores dos "kits" da Operon Technologies, Alameda, CA, (OPA1, OPA10, OPA19, OPC10, OPC11, OPC14, OPI1, OPI2, OPY19 e OPY20) e da "British Columbia University” (UBC 105). Os produtos das reações de amplificação foram separados por eletroforese em gel submerso de agarose a $1,2 \%$, onde migraram sob diferença de potencial de $80 \mathrm{~V}$ por um período médio de três horas e trinta minutos. Foram corados com brometo de etídio ( $50 \mu \mathrm{g}$ por gel de 100
$\mathrm{mL})$, e fotografados sob luz ultravioleta (302 nm).

As cultivares foram genotipadas através dos produtos visualizados em gel de agarose e uma matriz de presença/ ausência de bandas foi gerada servindo de base para a análise de similaridade genética, com o uso do coeficiente de Jaccard. A partir da matriz de similaridade, os genótipos foram agrupados pelo método da média aritmética não ponderada (UPGMA). A consistência do dendrograma formado foi avaliada pelos métodos de bootstrap (considerando-se 1000 reamostragens) e coeficiente de correlação cofenética. Estas análises foram efetuadas através do programa Bionumerics (Applied Maths, Kortrijk, Bélgica). A fidelidade entre o dendrograma gerado e a matriz de similaridades que lhe deu origem foi avaliada pelo teste de Mantel (1967).

\section{RESULTADOS E DISCUSSÃO}

Os 11 iniciadores geraram 140 (86,4\%) bandas polimórficas, sendo que o número de fragmentos por iniciador variou de 10 (UBC105) até 18 (OPA10, OPC11, OPI1) com uma média de 15 bandas por iniciador. Valor semelhante (12,5 bandas por iniciador) foi obtido por Masuelli \& Galmarini (1996) com a caracterização de quatro cultivares argentinas de cebola pela técnica de RAPD, também com a utilização de iniciadores da Operon Technologies (OPA3, OPA4, OPA8, OPA11, OPA13). Um valor inferior, de número médio de bandas por iniciador $(5,6)$, foi encontrado por Arifin et al. (2000) quando avaliaram a diversidade genética do gênero Allium (A. cepa var. ascalonicum e $A$. x wakegi), em que obtiveram de 1 a 14 bandas por iniciador.

No estudo de diversidade genética entre quatro espécies do gênero Allium e de sete cultivares de cebola, Wilkie et al. (1993) testaram 20 iniciadores RAPD. Nas análises interespecíficas quase todos os iniciadores foram polimórficos, com grandes variações nos padrões de bandas, enquanto na intraespecífica sete iniciadores apresentaram polimorfismo. Diferentemente, Arifin et al. (2000), obtiveram um número bem inferior de 


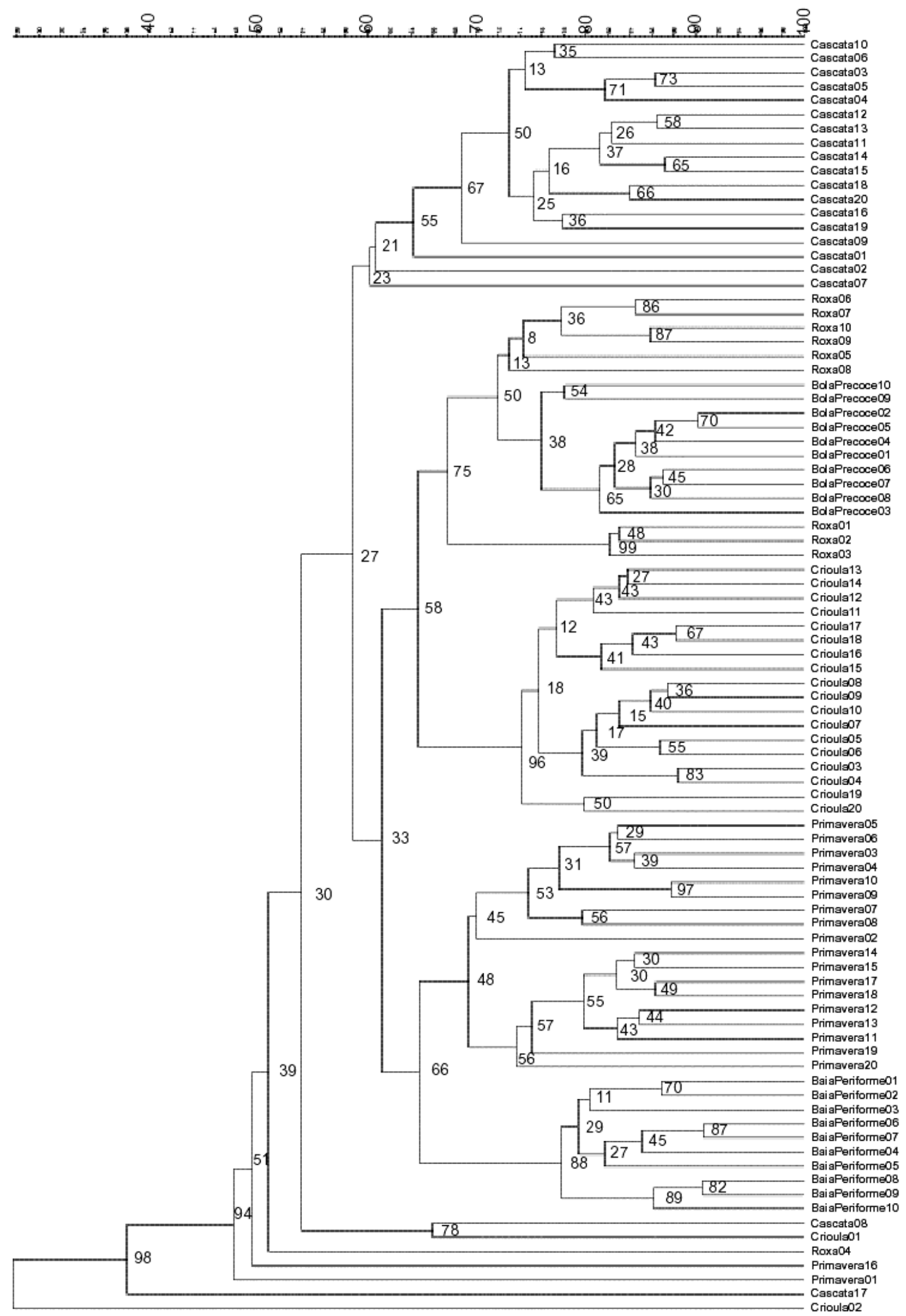

Figura 1. Agrupamento (UPGMA) de 90 genótipos de cebola com base na similaridade genética (coeficiente de Jaccard). Os valores de bootstrap (\%) estão indicados nos nós correspondentes de cada agrupamento (grouping (UPGMA) of 90 onion genotypes based on genetic similarity (Jaccard coefficient). The bootstrap values (\%) are indicated in the corresponding nodes in each group). Pelotas, Embrapa Clima Temperado, 2005. 
iniciadores polimórficos em relação ao total testado. De 100 iniciadores de RAPD analisados, apenas 20 foram polimórficos na avaliação de diversidade genética do gênero Allium (A. cepa var. ascalonicum e $A$. x wakegi).

A similaridade intravarietal foi $73,8 \%$ e $86,7 \%$, respectivamente, para 'BRS Cascata' e 'Baia Periforme'. Para os demais materiais, os resultados foram: 'Crioula', 77,4\%, 'Roxa', 76,8\%, 'Bola Precoce', 84,2\%, e 'Primavera', $75,2 \%$ (Figura 1).

$\mathrm{Na}$ avaliação intervarietal, os genótipos apresentaram uma similaridade média de $63 \%$ e a análise de agrupamento permitiu a formação de três grupos maiores unindo as cultivares de mesma população de origem (Figura 1). Estes três agrupamentos formados pelo método de UPGMA foram sustentados por valores em cada nó de 55\%, 58\% e 66\% (Figura 1) de replicações similares para as 1.000 permutações conduzidas pelos bootstraps e por valores correspondentes de $85 \%, 90 \%$ e $88 \%$ quando da análise do coeficiente de correlação cofenética, sendo estes valores considerados relativamente altos. Cabe destacar que o coeficiente de correlação de Mantel foi de 0,84, para 10.000 permutações, indicando concordância satisfatória entre a matriz de dados e o agrupamento.

Estes três grupos correspondem às principais populações de base das cultivares brasileiras, que são Baia Periforme, Crioula e Pêra (Oliveira et al., 2004). Alguns indivíduos (menos de $10 \%$ do total) avaliados não agruparam aos demais. Semelhantes resultados, de obtenção de grupos conforme a origem, na avaliação da similaridade genética de cultivares de uma espécie de Allium, com a utilização da técnica de RAPD, foram encontrados por Mota et al. (2006). Neste trabalho a caracterização molecular permitiu a discriminação de cultivares de alho conforme o seu grupo semi-nobre ou nobre.

Dos três grupos formados (Figura 1) pelas principais populações de cebola brasileiras, o primeiro é o da Pêra, representado no trabalho, pela cultivar BRS Cascata. Esta foi desenvolvida a partir de seleção massal da 'Pêra Norte', cultivar pertencente à população Pêra.
'BRS Cascata' contém bulbos na forma de pião, com coloração das escamas marrom-escuro e ótima conservação pós-colheita (Leite et al., 2002). A população Pêra provavelmente é originária de populações egípcias da África do Norte, que, após introdução na Ilha dos Açores, chegaram ao Brasil trazidas pelos imigrantes (Barbieri \& Medeiros, 2007).

O segundo grupo é o da população Crioula. Esta foi a população responsável pelo desenvolvimento da cultura da cebola no estado de Santa Catarina. Através do isolamento geográfico natural de áreas agrícolas neste estado, é que se deu a conservação da diversidade genética desta população. Este grupo está representado no trabalho pelas cultivares Bola Precoce, Crioula e Roxa. A 'Crioula' e a 'Roxa' são derivadas diretamente da população Crioula e 'Bola Precoce' e tem sua origem na terceira população representada no trabalho, que é a Baia Periforme. Uma possível explicação para a cultivar Bola Precoce situar-se no grupo da Crioula, é que possivelmente a população Crioula também tenha germoplasma de Baia Periforme em sua origem (Barbieri \& Medeiros, 2007).

O grupo da população de Baia Periforme está representado no trabalho por genótipos das cultivares Baia Periforme e Primavera. 'Primavera' é uma cultivar derivada de uma população de Baia Periforme do litoral sul do Rio Grande do Sul, que apresenta bulbos de formato globular, coloração das escamas alaranjada e ciclo precoce (Garcia, 1992).

A 'Baia Periforme' é um germoplasma descendente da cultivar portuguesa Garrafal, a qual foi introduzida pelos imigrantes portugueses da Ilha dos Açores na Região Sul do Brasil. É o germoplasma mais utilizado nos programas de melhoramento de todo o País (Gomes \& Maluf, 1995). Melo \& Boiteux (2001) listaram aproximadamente 50 cultivares de cebola obtidas no Brasil, por instituições públicas e privadas, a partir de Baia Periforme, no período de 1938 a 2000.

Constatou-se divergência genética tanto entre cultivares como dentro de uma mesma cultivar de cebola recomendada para a Região Sul do Brasil em estudo, o que confirma o potencial de serem exploradas em trabalhos de melhoramento genético para o desenvolvimento de genótipos superiores.

\section{AGRADECIMENTOS}

Os autores agradecem ao Dr. Eliseu Binneck, pesquisador da Embrapa Soja, pela colaboração nas análises estatísticas.

\section{REFERÊNCIAS}

ARIFIN NS; OZAKI Y; OKUBO H. 2000. Genetic diversity in Indonesian shallot (Allium cepa var. ascalonicum) and Allium $\mathrm{x}$ wakegi revealed by RAPD markers and origin of A. x wakegi identified by RFLP analyses of amplified chloroplast genes. Euphytica 111: 23-31.

BARBIERI RL; LEITE DL; CHOER E; SINIGAGLIA C. 2005. Divergência genética entre populações de cebola com base em marcadores morfológicos. Ciência Rural 35: 303-308.

BARBIERI RL; MEDEIROS ARM. 2007. A cebola ao longo da história. In: BARBIERI RL (ed.). Cebola: ciência, arte e história. 2. ed. Brasília: Embrapa Informação Tecnológica. p.13-20.

BRADEEN JM; HAVEY MJ. 1995. Randomly amplified polymorphic DNA in bulb onion and its use to asses inbred integrity. Journal of the American Society for the Horticultural Science 120: 752-758.

BREWSTER JL. 1994. Onion and other vegetable alliums. Cambridge: University Press. 236 p.

BUZAR AGR. 2005. Diversidade genética e identificação de citoplasma macho-estéril em germoplasma de cebola. Brasília: UNB: FAMV. 110 p. (Tese mestrado).

CRAMER CS; HAVEY MJ. 1999. Morphological, biochemical, and molecular markers in onion. HortScience 34: 589-593.

FRANÇAJGE; CANDEIAJA. 1997. Development of short-day yellow onion for tropical environments of the Brazilian northeast. Acta Horticulturae 433: 285-287.

FERREIRA ME; GRATTAPAGLIA D. 1998. Introdução ao uso de marcadores moleculares em análise genética. 3. ed. Brasília: EMBRAPA-CENARGEN. 220p.

GARCIA A. 1992. Cultivar Primavera: cebola para colheita em épocas de melhores preços. Hortisul 2: 32-37.

GOLDMAN IL; SCHROECK G; HAVEY MJ. 2000. History of public onion breeding programs and pedigree of public onion germplasm releases in the United States. Plant Breeding Reviews 20: 67-103.

GOMES LAA; MALUF WR. 1995. Avaliação de híbridos intervarietais de cebola (Allium cepa L.) 'Pira Ouro' x 'Pirana Precoce no sistema de bulbinhos. Ciência e Prática 19: 233-240. 
HANELT P. 1990. Taxonomy, evolution and history. In: RABINOWITCH HD; BREWSTER JL (eds). Onion and allied crops. Boca Raton: CRC Press, 1, p.1-26.

HAVEY MJ; KING JJ; BRADEEN JM; BARK O. 1996. Molecular markers and mapping in bulb onion, a forgotten monocot. HortScience 31: 1116-1118.

KING JJ; BRADEEN JM; BARK O; Mc CALLUM JA; HAVEY MJ. 1998. A lowdensity genetic map of onion reveals a role for tandem duplication in the evolution of an extremely large diploid genome. Theorethical and Applied Genetics 96: 52-62.

KLAAS M; FRIESEN N. Molecular markers in Allium. 2002 In: RABINOWITCH HD; CURRAH L (eds.). Allium crop science: recent advances. Wallingford: CABI Publishing. p.159-185.

LANCASTER JE; BOLAND MJ. 1990. Flavor biochemistry. In: RABINOWITCH HD; BREWSTER JL. (eds.) Onion and allied crops. Boca Raton: CRC Press, 1, p.33-72.

LEITE, DL. 2007. Melhoramento genético de cebola. In: BARBIERI RL (Ed.). Cebola: ciência, arte e história. 2. ed. Brasília: Embrapa Informação Tecnológica. p.79-113.

LEITE DL; GARCIA A; SANTOS AM. 2002. BRS Cascata a new cultivar released by Temperate Climate Agricultural Research Center, Embrapa, Brazil. In: NATIONAL ALLIUM RESEARCH CONFERENCE, 2002, Pasco. Abstracts...Pasco: Washington State University. p.56.

MASUELLI RW; GALMARINI CR. 1996. RAPDs to distinguish among four argentine onion cultivars. Allium Improvement Newsletter 6:10-12.

MELO PCT; BOITEUX LS. 2001. Análise retrospectiva do melhoramento genético de cebola (Allium cepa L.) no Brasil e potencial aplicação de novas estratégias biotecnológicas. Disponível em:http://www. sbmp.org.br/cbmp2001/palesras/palestra 18.htm. Acessado em: 17 junho de 2003.

MOTA JH; RESENDE GM; SOUZA RJ. 2006. Similaridade genética de cultivares de alho pela comparação de caracteres morfológicos, físico-químicos, produtivos e moleculares. Horticultura Brasileira 24: 156-160.

OLIVEIRA VR; LEITE DL; SANTOS CAF; COSTA ND; MELO PCT. Cultivares. In: Sistema de produção de cebola (Allium cepa L.). Brasília: Embrapa Hortaliças, 2004. Versão eletrônica. (Embrapa Hortaliças. Sistemas de Produção, 5). Disponível em http://www.cnph. embrapa.br/sistprod/cebola/cultivares.htm. Acessado em 31 de outubro de 2006.

MANTEL NA. 1967. The detection of disease clustering and a generalized regression approach. Cancer Research 27: 209-220.

WILKIE SE; ISAAC PG; SLATER RJ. 1993. Randon amplified polymorphic DNA(RAPD) markers for genetic analysis in Allium. Theorethical and Applied Genetics 86: 497504. 